\title{
Hernández García, Elizabeth. José de la Riva-Agüero y Sánchez Boquete (1783-1858), primer presidente del Perú. Lima: Fondo Edito- rial del Congreso del Perú e Instituto Riva-Agüero, 2019, 310 pp.
}

Teniendo en cuenta su envergadura, este trabajo no es solo «un intento biográfico intelectual» de José de la Riva-Agüero y Sánchez Boquete (229), como dice con modestia su autora. Más exacto sería considerarlo como todo un fresco de la Independencia peruana y de los primeros ańos de la República, que son descritos y analizados en torno a la trayectoria de Riva-Agüero, temprano conspirador a favor de la Independencia desde antes de la Expedición Libertadora de 1820, primer presidente de la República en 1823 y, ya en un tiempo posterior, presidente del estado Nor-Peruano en el tiempo de la Confederación Peruano-Boliviana en 1838. Fue un personaje que mantuvo hasta el final sus ideas monárquicas moderadas. Para reconstruir esta trama, Hernández hace un diestro cruce de información entre fuentes primarias cercanas a los acontecimientos y las Memorias y documentos para la historia de la Independencia del Perú y causas del mal éxito que ha tenido esta, obra póstuma de 1858 que Riva-Agüero firmó bajo el seudónimo de Pruvonena. También hace un importante estudio sobre el pensamiento político de este personaje en las diferentes épocas de su vida (53-71; 155-160; 222-231).

Debe destacarse que el libro se mueve en torno al análisis del discurso peruano (74) sobre de Independencia. De hecho, aunque la propia autora no lo presenta así, este trabajo es, de hecho, una exploración pertinente, y en muchos casos inédita, en esta línea. Es muy importante destacar que los procesos de independencia de la América española —en particular el proceso internacional — han sido muchas veces reconstruidos en base al uso privilegiado y masivo de fuentes originadas en actores e instituciones no peruanas. Esta circunstancia puede haber influido en los investigadores que se han interesado en el tema en el sentido de oscurecer, e incluso deformar, el mencionado discurso y la apreciación 
de los intereses peruanos sobre la Independencia. Son dos los temas que deben destacarse sobre esto último.

En primer lugar, Hernández afirma que Riva-Agüero encabezó todo un sector de la élite peruana que buscó la Independencia, de manera activa, desde antes de la llegada de la expedición de José de San Martín. A su entender, cuestiona la afirmación del historiador británico John Lynch, quien afirmó en su libro Las revoluciones hispanoamericanas (1808-1826) que la mayor parte de los liberales peruanos buscaban la reforma y no la revolución, y que no estaban preparados "para poner en peligro su predominio social por amor la independencia» (43). Se trata de un cuestionamiento en lo esencial correcto, aunque cabe hacer unos pocos comentarios. En 1821, cancelada por el virrey José de la Serna de manera irracional una propuesta monárquica de San Martín para declarar la independencia y unir los ejércitos patriota y realista (como iba a ocurrir en México más o menos por esa época), el general rioplatense entró a Lima y proclamó la independencia, para formar luego un «Protectorado», que desilusionó mucho a los peruanos: tanto la jefatura como dos de los tres ministerios fueron puestos en manos de extranjeros. Hernández destaca muy bien la decepción de Riva-Agüero y de su grupo frente a esta situación, pues propiciaba la intervención de extranjeros en los asuntos del Perú ¿Ello ocurrió porque, como dice el historiador argentino Bartolomé Mitre, San Martín no encontró «un solo hombre» en el Perú capaz de tomar las riendas del gobierno? (74 y ss.) ¿O porque Riva-Agüero y su grupo representaban más bien un sector pequeño y débil que propiciaba la Independencia dentro del conjunto de una elite de corazón más bien realista? Aquí Hernández introduce una sagaz reflexión historiográfica aclaratoria que se orienta a revisar la imagen idealizada que la historiografía argentina, e incluso de otros países, construyó sobre San Martín como «libertador imprescindible». Y añadamos nosotros: la marginación relativa de Riva-Agüero y de sus partidarios, ¿no se habrá debido a que la auténtica y soterrada causa de la intervención chileno-rioplatense fue la neutralización económica y militar del Perú como foco peligroso para los nuevos estados del sur? El propio Riva-Agüero pintó a San Martín como «un aventurero que 
buscaba su fortuna particular» y a Bernardo de Monteagudo, su mano derecha, como un personaje altanero y feroz, cuyas medidas «helaron los corazones de los patriotas, y arruinaron al Perú con sus medidas tiránicas». En pocas palabras, el gobierno de los «libertadores» comenzó a sentirse como un "mayor despotismo» frente al que habían ejercido los españoles «en tres siglos» (75-8). Si estas apreciaciones son correctas, Riva-Agüero debe haber sido visto por personajes como Monteagudo, y el propio San Martín, como un peligro.

En segundo lugar, la historiografía tradicional dice que, en 1823, RivaAgüero aceptó la llegada de Bolívar y que luego, «cambió de bando» y se pasó al virrey, traicionando al Perú. El gran logro del libro de Hernández es haber desmontado este mito. Lo que ocurrió es que, para 1823, RivaAgüero ya se había convertido en un líder con arraigo popular entre la población de origen africano y los montoneros de los Andes centrales. De hecho, encarnaba entonces el patriotismo peruano, como señala el historiador chileno Gonzalo Bulnes en su libro Las últimas campañas de la Independencia del Perú (1822-1826) de 1897. Uno de sus aliados más cercanos fue Ignacio Quispe Ninavilca, guerrillero de Huarochirí, quien por esos días lo defendió así, en una cita que ha sido reproducida por el historiador ecuatoriano Jaime Rodríguez en su libro La independencia de la América española: "Colombia ha venido a invadir nuestros hogares y saciar su ambición con el fruto de nuestro trabajo. ¿Cómo es posible permitir que esta raza aventurera nos subyugue y aniquile nuestra sangre? [...] A ese monstruo [Bolívar], paisanos, que pretende llevarnos a esclavizar en sus pueblos en Colombia y traer acá colombianos [...] lo apoyan en Lima y sostienen su crueldad cuatro aduladores [...] solo Riva-Agüero es quien ha de salvarnos de las uñas de estas fieras» (397-398). Esta situación de Riva-Agüero como líder popular preocupó a Bolívar, quien descartaba del todo la presencia de algún $\mathrm{O}^{\prime}$ Higgins peruano que pusiera límites a la autoridad absoluta que requería para imponer sus puntos de vista y abrir campo futuro a la dominación del Perú por Colombia. Como hemos adelantado, Riva-Agüero terminó acercándose al virrey La Serna, pero con el objeto de proponerle un plan muy parecido al que San Martín había expresado en la hacienda Punchauca en 1821: unir los 
ejércitos peruanos patriota y realista y proclamar la independencia de un Perú monárquico, haciendo así innecesaria la intervención colombiana. Debe destacarse que Riva-Agüero no había modificado un ápice su propósito de conseguir la independencia del Perú. Lo que quería -y aquí acudo a un lúcido pasaje del libro de Hernández- era conseguir este objetivo negociando con Espańa, dentro del sistema, como había ocurrido en 1821 en el caso de México, sin la «ambiciosa injerencia» de extranjeros (la expresión es del bisnieto José de la Riva-Agüero y Osma) (158 y ss.) Bien dice Hernández que no puede considerarse traidor a un peruano que luchó por conseguir la independencia de su patria buscando prescindir de tropas de intervención de otros países (155 y 158). En este punto, Hernández no precisa sino solo sugiere (y sorprende que no incluya en su libro la opinión de Quispe Ninavilca sobre Bolívar). Riva-Agüero sabía desde la segunda mitad de 1821 de los abusos que los colombianos estaban cometiendo en Guayaquil y Quito «bajo el velo de amigos y protectores» (109). No fue ni de lejos el único peruano de primera línea que receló de los colombianos antes de su llegada, como lo atestigua el caso de Hipólito Unanue (159). Deben haber existido motivos más profundos que la negativa de Bolívar a respaldar a Riva Agüero para que optara por acercarse al virrey (149). Pero, por lo visto, no fueron señales contundentes para él. Como le pasó un poco después a Torre Tagle, Riva-Agüero parece haber comprendido de manera tardía, y ya disipado el velo ideológico que cubría las crudas realidades geopolíticas, el peligro que representaba Colombia para la soberanía del Perú naciente y la auténtica naturaleza de la intervención bolivariana.

Hugo Pereyra Plasencia Academia Nacional de la Historia 